\title{
Bilateral congenital venous tortuosity and dilatation combined with cilioretinal artery: a photographic essay
}

This article was published in the following Dove Press journal:

International Medical Case Reports Journal

7 April 2016

Number of times this article has been viewed

Nuo $X u^{1}$

Yi Cui ${ }^{2}$

Zhonghai Gao'

'Department of Ophthalmology, Fujian Provincial Hospital, ${ }^{2}$ Department of Ophthalmology, The Union Hospital of Fujian Medical University, Fuzhou City, Fujian Province, People's Republic of China
Correspondence: Nuo Xu

Department of Ophthalmology, Fujian Provincial Hospital, No. I 34 East Street, Dongjie, Gulou District, Fuzhou City, Fujian Province, 35000I, People's Republic of China

Tel $+8659 \mid 87557768$

Fax +8659187532356

Email es_muss_sein@foxmail.com
Abstract: To report the case of bilateral congenital venous tortuosity and dilatation combined with cilioretinal artery. A 48-year-old woman complained of headache and underwent routine ophthalmic examination. The best-corrected visual acuity was 20/20 in both eyes. The examination of the fundus through a dilated pupil revealed that the retinal veins were strikingly tortuous and slightly dilated in the posterior pole and mid-peripheral retina of both eyes. However, the course and shape of the veins were normally straight in the peripheral retina. There was no change in the appearance and shape of the vein. The visual acuity remained unaffected during a 2-year follow-up.

Keyword: retinal vascular anomalies, retinal disease, retinal vessels, cilioretinal artery, retina, congenital

\section{Introduction}

Various types of congenital anomalies of retinal vessels may occur, including congenital huge retinal macrovessel, arteriolar-arterial or veno-venous crossing, triple branching, congenital tortuosity, prepapillary loop, anomalous macular vessel, arteriovenous communication, and cilioretinal vessel. Excluding the last one, the low incidence and lack of visual deficit make an accurate prevalence estimate of these anomalies difficult. ${ }^{1}$ Congenital venous tortuosity is an aberrant retinal vessel that is usually located at the posterior pole region. Most of these cases are unilateral and stable with excellent visual prognosis and are detected on routine examination.

To our knowledge, bilateral retinal venous tortuosity and dilatation combined with cilioretinal artery is rare. Herein, we report a case of bilateral asymptomatic congenital anomalous tortuosity and dilatation of the retinal veins in conjunction with cilioretinal artery with normal visual acuity and fluorescein angiography findings.

\section{Case description}

A 48-year-old woman complained of headache and underwent routine ophthalmic examination. She denied any cardiovascular risk factors, such as hypertension, diabetes, and hyperlipidemia. Furthermore, we asked about the family history and examined the fundus of close family members. No abnormality was observed. On ocular examination, the best-corrected visual acuity was 20/20 in both eyes. Noncontact tonometry examination disclosed the intraocular pressure to be $18.3 \mathrm{mmHg}$ in the right eye and $17.8 \mathrm{mmHg}$ in the left eye. The slit-lamp examination of the anterior segment was unremarkable. The examination of the fundus through a dilated pupil revealed that 


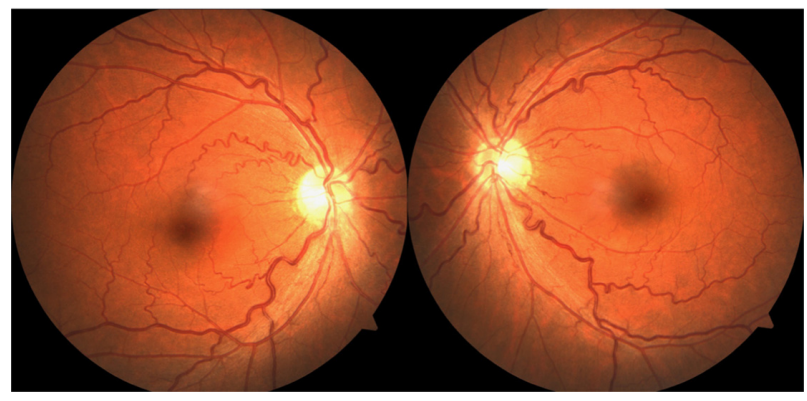

Figure I Fundus photographs showing veins are convoluted and slightly dilated, but arteries have straight courses.

the retinal veins were strikingly tortuous and slightly dilated in the posterior pole and mid-peripheral retina of both eyes. However, the course and shape of the veins were normally straight in the peripheral retina (Figure 1). Additionally, funduscopy showed vessels that appeared from behind the disc margin and coursed inferotemporally toward the fovea in the posterior retina, which were considered to be cilioretinal arteries (Figure 2).

Fluorescein angiography of the right eye demonstrated that the arteries begin to fluoresce at 13.7 seconds as the choroid fluoresces (Figure 3), rather than as the retina fluoresces. Furthermore, the fluorescein angiogram of the arteriovenous phase showed obviously tortuous and dilated retinal veins without any leakage or dye (Figure 4).

All the supplementary tests, such as contrast sensitivity, color test, Amsler grid, and electrophysiologic test, were

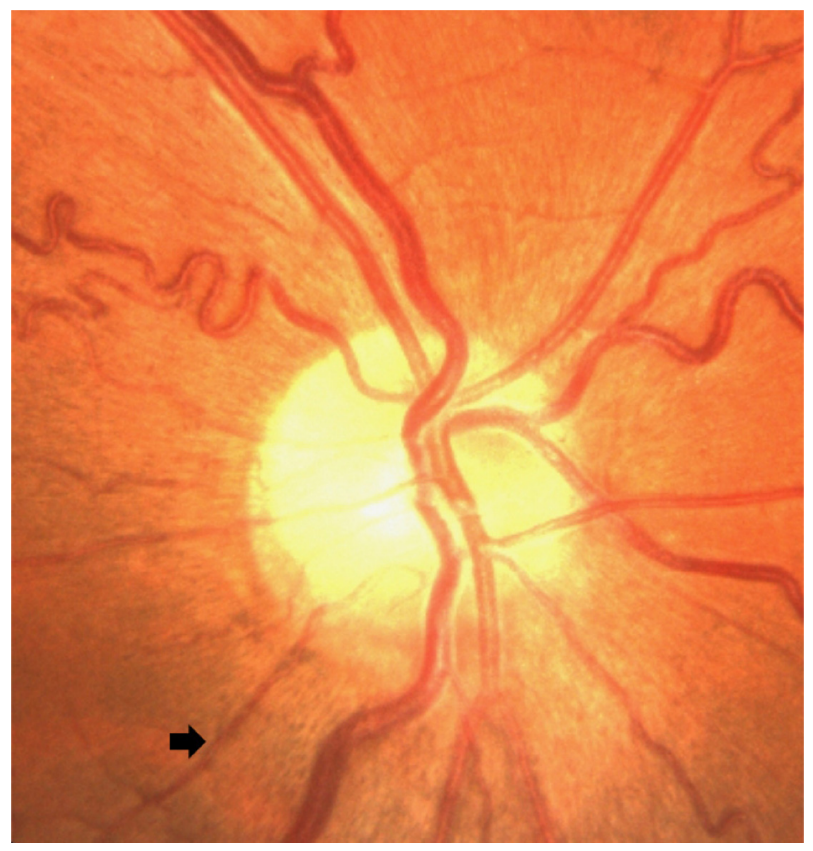

Figure 2 The cilioretinal artery course inferotemporally from behind the disc margin (arrow).

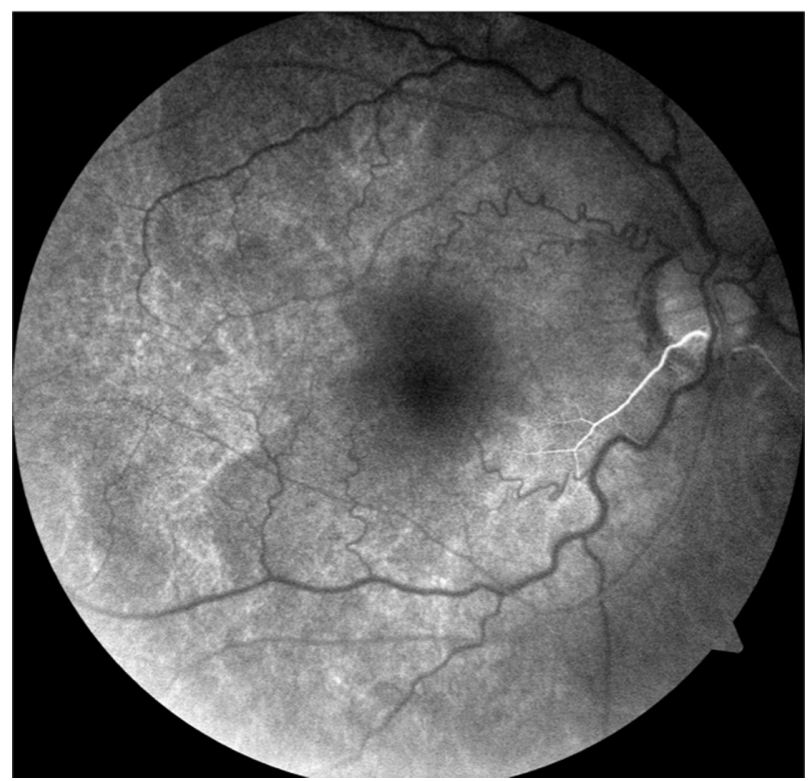

Figure 3 The cilioretinal artery begins to fluoresce at early phase angiogram (I3.7 seconds).

normal. The visual field test using a 10-2 threshold Humphrey computerized automated perimeter was also normal.

During a 2-year follow-up visit, the patient was monitored for visual acuity, intraocular pressure, silt-lamp anterior segment examination, and ophthalmoscopic examination. There was no change in the appearance and shape of the vein, and the visual acuity remained unaffected. This report was approved by the human ethics committee of the Fujian Provincial Hospital, and informed written consent was obtained from the patient.

\section{Discussion}

The anomalous tortuosity and dilatation of the retinal vessel without other abnormality is rare, making the accurate estimation of incidence difficult. Gauss ${ }^{2}$ estimated that the tortuosity of retinal arteries alone was twice as common as that of the veins. Walsh and Hoyt ${ }^{3}$ and Awan, ${ }^{4}$ however, hold an opposing view. In a retrospective analysis that evaluated

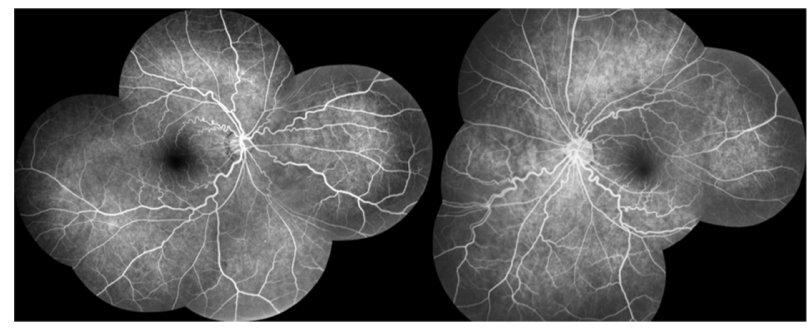

Figure 4 FFA photography of both eyes showing obviously tortuous and dilated retinal veins.

Note: No leakage or evidence of dye is seen.

Abbreviation: FFA, fluorescein fundus angiography. 
the anomalies of the retinal veins in 1,400 healthy individuals, only one had striking tortuosity that affected only the veins and only two had striking dilatation of the retinal veins. ${ }^{4}$ The retinal veins described in the current report were twice the width of the corresponding arteries, and their tortuosity was striking and corkscrew in type. Although the patient had no specific underlying complications that contributed to the development of this vascular anomaly, hemorrhages and vein occlusion may be associated with this retinal vessel variant. The hemorrhages tend to be absorbed spontaneously in a short period without any complication. ${ }^{5}$ Khan $^{6}$ reported a case of branch retinal vein occlusion with venous tortuosity at the optic disc, which contributed to the obstruction of the normal variant of vein vasculature. Theodossiadis ${ }^{7}$ reported a case of coexistence of retinal venous anastomoses with optic disc coloboma and pit. Except for these two cases, no severe complication had been reported previously. There are other conditions secondary to retinal vascular diseases that share similar venous characteristics, and hence must be differentiated from congenital venous tortuosity. The former often showed hemorrhage, microaneurysms, and exudation with retinal and macular edema. Fluorescein fundus angiography (FFA) showed the slow blood flow and fluorescein leakage in retinal vessels.

Cilioretinal arteries are the most common congenital vascular anomalies of the retina, with an occurrence rate of $\sim 17 \%-35 \%$. ${ }^{1,8}$ Generally, cilioretinal arteries are shown to originate from posterior ciliary arteries and extend to the macula from the optic disc, such as that in the case we described. In some instances, they can extend to the superotemporal or superonasal retina. ${ }^{1}$ However, the combination of cilioretinal artery and other retinal abnormalities is rare. We therefore report this unusual case of two types of retinal vascular abnormalities.

\section{Acknowledgment}

This study was supported by a grant from the Youth Innovation Foundation of Fujian Provincial Health and Family Planning Commission (No.2015-1-10).

\section{Disclosure}

The authors report no conflicts of interest in this work. The authors alone are responsible for the content and writing of the paper.

\section{References}

1. Awan, KJ. Arterial vascular anomalies of the retina. Arch Ophthalmol. 1977;95(7):1197-1202.

2. Gauss H. Normal and Abnormal Development: Congential Deformities. In: System of Ophthalmology, Vol 3, pt 2. St Louis, MO: CV Mosby Co.; 1963:784

3. Walsh FB, Hoyt WF. Clinical Neuro-Ophthalmology. 3rd ed. Baltimore, MD; Williams \& Wikins; 1969:683-684.

4. Awan, KJ. Anomalies of the retinal veins and their incidence. $J$ Pediatr Ophthalmol. 1976;13(6):353-359.

5. Xu M, Lv PL. Clinical characters and classification of the congenital retinal vascular anomalies. Int J Ophthalmol. 2011;11(3):528-530. Chinese.

6. Khan J, Chong V. Two retinal vein occlusions in a patient with venous tortuosity at the optic disc. Graefes Arch Clin Exp Ophthalmol. 2007; 245(2):313-314.

7. Theodossiadis GP, Damanakis AG, Theodossiadis PG. Coloboma of the optic disk associated with retinal vascular abnormalities. Am J Ophthalmol. 1995;120(6):798-800.

8. Liu L, Liu LM, Chen L. Incidence of cilioretinal arteries in Chinese Han population. Int J Ophthalmol. 2011;4(3):323-325.
International Medical Case Reports Journal

\section{Publish your work in this journal}

The International Medical Case Reports Journal is an international, peer-reviewed open-access journal publishing original case reports from all medical specialties. Previously unpublished medical posters are also accepted relating to any area of clinical or preclinical science. Submissions should not normally exceed 2,000 words or

\section{Dovepress}

4 published pages including figures, diagrams and references. The manuscript management system is completely online and includes a very quick and fair peer-review system, which is all easy to use. Visit http://www.dovepress.com/testimonials.php to read real quotes from published authors. 